\title{
Massive lower gastrointestinal bleeding due to Dieulafoy's lesion in sigmoid colon
}

\author{
Sigmoid kolonda Dieulafoy lezyonuna bağlı massif alt gastrointestinal kanama
}

\author{
(DSSehmus ÖLMEZ, (D) Bünyamin SARITAŞ, (D)Yılmaz ÇELIK, D Adnan TAŞ, D Nevin AKÇAER ÖZTÜRK \\ Department of Gastroenterology, University of Health Sciences, Adana City Training and Research Hospital, Adana, Turkey
}

\section{Dear Editor;}

Dieulafoy's lesion (DL) is one of the rare lesions observed in endoscopy. These lesions are usually observed in upper gastrointestinal system and mostly in the stomach. DL in colon is extremely rare (1). Herein we report a very rare case of DL in sigmoid colon presenting with severe hematochezia and successfully treated with endoclips.

A 78-years-old female patient admitted to our emergency department with severe hematochezia. She had previous history of hypertension and endometrium carcinoma. She was using nonsteroid anti-inflammatory drugs and taking no medicine for hypertension. On physical examination blood pressure was 120/70 $\mathrm{mmHg}$ and pulse rate were 95 beats per minute and regular. Physical examination was normal except for hematochezia on rectal examination and incision scar on suprapubic region. Laboratory examination on admission was as follows: hemoglobin: $6.6 \mathrm{~g} / \mathrm{dl}$ (normal range: $10.9-14,3 \mathrm{~g} / \mathrm{dl}$ ), urea: $93 \mathrm{mg} /$

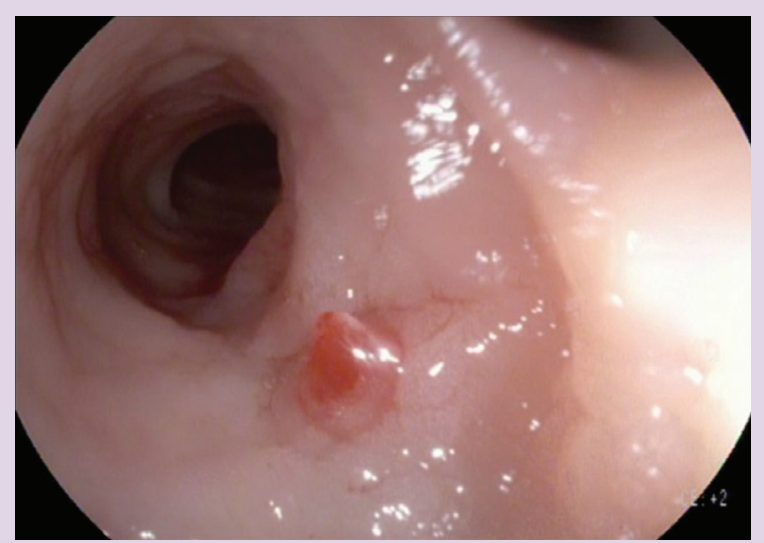

Figure 1. Protruding Dieulafoy's lesion.

Correspondence: University of Health Sciences, Adana City Training And Research Hospital Department of Gastroenterology, Adana Tel: +90 3224559000

E-mail: drsehmusolmez@gmail.com dl (normal range: 17 - $43 \mathrm{mg} / \mathrm{dl}$ ), creatinine: 1.2 (normal range: $0.51-0.95 \mathrm{mg} / \mathrm{dl}$ ), albumin: $33 \mathrm{gr} / \mathrm{L}$ (normal range: 35 - 55g/L), total protein: $53 \mathrm{~g} / \mathrm{L}$ (normal range: 66 - $83 \mathrm{~g} / \mathrm{L}$ ), and other laboratory parameters were normal.

Upper and lower endoscopy performed emergently. Upper endoscopy was normal. Lower endoscopy was suboptimal and advanced into distal part of descending colon, there was fresh blood in all visible colon sections and therefore the source of bleeding could not be found. Patient was followed in intensive care unit. A total of three units of erythrocyte suspension were infused. Two days later, second look colonoscopy performed. DL was found as a protruding vascular lesion in sigmoid colon (Figure 1, and 2). Two endoclips were applied to the DL (Figure 3). She was discharged after six days. No bleeding recurred after 6 months. The patient gave written consent regarding this letter. 


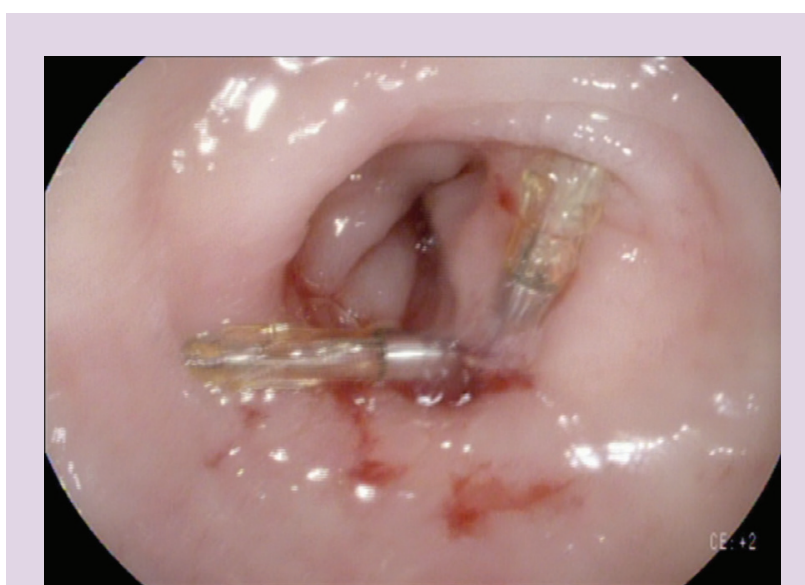

Figure 3. Dieulafoy's lesion after endoclip application.

In all patients presenting with gastrointestinal bleeding, DL must be kept in mind in differential diagnosis at first, since it can be fatal (2). Since DLs are small lesions with surrounding normal mucosa, it can easily be overlooked if the lesion was not bleeding (3). Our patient was diagnosed in the second endoscopy. Although different treatment modalities exist for the treatment of $\mathrm{DL}$, endoclip application is safe and effective therapeutic option, and it can be easily performed and may be lifesaving. Since colonic wall is thinner than gastric wall, to avoid mechanical and heat injury in colonic $\mathrm{DL}$, endoclip or band ligation may be more suitable treatment modalities for these lesions (4).

Conflict of Intererest: All of the authors declare no conflict of intererest regarding this article.

\section{REFERENCES}

1. Paccos JL, Mukai NS, Correa PAFP, et al. Dieulafoy lesion in the colon: a rare cause of lower gastrointestinal bleeding. Endoscopy 2021;53:E313-4.

2. Baxter M, Aly EH. Dieulafoy's lesion: current trends in diagnosis and management. Ann R Coll Surg Engl 2010;92:548-54.

3. Jeon HK, Kim GH. Endoscopic management of Dieulafoy's lesion. Clin Endosc 2015;48:112-20.

4. Nojkov B, Cappell MS. Gastrointestinal bleeding from Dieulafoy's lesion: Clinical presentation, endoscopic findings, and endoscopic therapy. World J Gastrointest Endosc 2015;7:295-307. 